\title{
Variance component estimates for alternative litter size traits in swine
}

Article in Journal of Animal Science · December 2015

DOI: $10.2527 /$ jas.2015-9416

CITATIONS

4

5 authors, including:

\section{Austin Putz}

lowa State University

8 PUBLICATIONS 9 CITATIONS

SEE PROFILE

\section{Christian Maltecca}

North Carolina State University

158 PUBLICATIONS 907 CITATIONS

SEE PROFILE
READS

108
Francesco Tiezzi

North Carolina State University

68 PUBLICATIONS 292 CITATIONS

SEE PROFILE

Kent A. Gray

Smithfield Premium Genetics

43 PUBLICATIONS 132 CITATIONS

SEE PROFILE

Some of the authors of this publication are also working on these related projects:

Genetic Variation Of Plasma Disposition Kinetics And Liver Gene Expression In The Pig And Their Implications On Animal Welfare And Drug Efficacy View project

BovMAS: Quantitative trait loci affecting milk production: mapping and utilization for marker assisted 


\title{
Variance component estimates for alternative litter size traits in swine
}

\author{
A. M. Putz, ${ }^{* 1}$ F. Tiezzi, ${ }^{*}$ C. Maltecca, ${ }^{*}$ K. A. Gray, $\dagger$ and M. T. Knauer* \\ *Department of Animal Science, North Carolina State University, \\ Raleigh 27695; †Smithfield Premium Genetics, Rose Hill, NC 28458
}

\begin{abstract}
Litter size at d 5 (LS5) has been shown to be an effective trait to increase total number born (TNB) while simultaneously decreasing preweaning mortality. The objective of this study was to determine the optimal litter size day for selection (i.e., other than d 5). Traits included TNB, number born alive (NBA), litter size at d 2, 5, 10, 30 (LS2, LS5, LS10, LS30, respectively), litter size at weaning (LSW), number weaned (NW), piglet mortality at d 30 (MortD30), and average piglet birth weight (BirthWt). Litter size traits were assigned to biological litters and treated as a trait of the sow. In contrast, NW was the number of piglets weaned by the nurse dam. Bivariate animal models included farm, year-season, and parity as fixed effects. Number born alive was fit as a covariate for BirthWt. Random effects included additive genetics and the permanent environment of the sow. Variance components were plotted for TNB, NBA, and LS2 to LS30 using univariate animal models to determine how variances changed over time. Additive genetic variance was minimized at d 7 in Large White and at d 14 in Landrace pigs. Total phenotypic variance for litter size traits decreased over the first $10 \mathrm{~d}$ and then stabilized. Heritability estimates
\end{abstract}

increased between TNB and LS30. Genetic correlations between TNB, NBA, and LS2 to LS29 with LS30 plateaued within the first $10 \mathrm{~d}$. A genetic correlation with LS30 of 0.95 was reached at d 4 for Large White and at $\mathrm{d} 8$ for Landrace pigs. Heritability estimates ranged from 0.07 to 0.13 for litter size traits and MortD30. Birth weight had an $\mathrm{h}^{2}$ of 0.24 and 0.26 for Large White and Landrace pigs, respectively. Genetic correlations among LS30, LSW, and NW ranged from 0.97 to 1.00 . In the Large White breed, genetic correlations between MortD30 with TNB and LS30 were 0.23 and -0.64 , respectively. These correlations were 0.10 and -0.61 in the Landrace breed. A high genetic correlation of 0.98 and 0.97 was observed between LS10 and NW for Large White and Landrace breeds, respectively. This would indicate that NW could possibly be used as an effective maternal trait, given a low level of cross-fostering, to avoid back calculating litter size traits from piglet records. Litter size at $\mathrm{d} 10$ would be a compromise between gain in litter size at weaning and minimizing the potentially negative effects of the nurse dam and direct additive genetics of the piglets, as they are expected to increase throughout lactation.

Key words: birth weight, genetic correlation, litter size at d 5, piglet survival
J. Anim. Sci. 2015.93:5153-5163 doi:10.2527/jas2015-9416

\section{INTRODUCTION}

Selection for litter size at d 5 (LS5) after farrowing has been suggested as an alternative trait to total number born (TNB) in swine breeding programs $(\mathrm{Su}$ et al., 2007). This trait was investigated as an alternative trait for selection to increase litter size at weaning due to the unfavorable association between TNB and piglet mortality (Johnson et al., 1999; Lund et al.,

\footnotetext{
${ }^{1}$ Corresponding author: putz.austin@gmail.com

Received June 13, 2015.

Accepted August 31, 2015.
}

2002; Bidanel, 2011). Due to this relationship, Danish breeders changed the main maternal trait from TNB to LS5 in 2004 (Nielsen et al., 2013). Selection for LS5 in Danish herds has increased TNB by 1.9 and 1.3 piglets per litter, while simultaneously decreasing mortality at $\mathrm{d} 5$ by 5.9 and $4.7 \%$ in Large White (LW) and Landrace (LR) pigs, respectively (Nielsen et al., 2013). Given the high genetic correlation between LS5 and litter size at weaning $\left(r_{a}=0.995\right.$; Su et al., 2007), it is expected that an increased number of piglets at $d$ 5 will directly increase the litter size at weaning, the main breeding objective in maternal lines. 
Su et al. (2007) reported the majority of preweaning mortality occurs within several days after farrowing. However, it is unclear why the Danish breeders specifically chose litter size at $d 5$. Utilizing a different litter size day for selection may optimize genetic progress for number of piglets weaned. Thus, an objective study is needed to identify how variances for litter size change from birth to weaning. Therefore, the objectives of this study were to 1) estimate variance components for litter size traits throughout lactation to determine the optimal day for selection and 2) estimate genetic correlations between litter size traits, total preweaning mortality, and average litter birth weight (BirthWt).

\section{MATERIALS AND METHODS}

Animal care and use committee approval was not obtained for this study because the data were obtained from an existing database. Standards of animal care met or exceeded the standards recommended by the national pork board for this study (National Pork Board, 2003).

\section{Data}

Smithfield Premium Genetics (Rose Hill, NC) provided data from the LW and LR breeds. Data from June 2009 through May 2013 were analyzed. All matings were performed by artificial insemination. At birth, the number of live born and stillborn piglets was recorded for each litter excluding mummified piglets. Litters were recorded, and piglets were processed and weighed within $48 \mathrm{~h}$ of birth along with cross-fostering. Cross-fostering was minimized when possible and occurred for 4.9 and $8.3 \%$ of the total number of live born piglets at birth and 17 and $25 \%$ of litters for LW and LR breeds, respectively. Preweaning mortality dates were recorded on individual piglets. Weaning age averaged $23.5 \mathrm{~d}$ for LW and $23.7 \mathrm{~d}$ for LR piglets.

Reproductive traits included TNB, number born alive (NBA), litter size of the biological dam at $\mathrm{d} 2$ through 30 (LS2 through LS30), litter size of the biological dam at weaning (LSW), mortality from birth through d 30 of age (MortD30), total number of piglets weaned by the nurse dam (NW), and BirthWt. Total number born was the sum of those born alive and stillborns. Traits starting with the prefix LS, referred to as LS traits, were calculated by aggregating piglet data and using the farrowing and mortality dates according to the biological litter (Nielsen et al., 2013). The LS traits were calculated by summing the number of preweaning mortalities, including stillborns up to that day and subtracting that sum from TNB. For example, LS5 would be calculated as TNB - stillborns - the sum of preweaning mortalities up to $\mathrm{d} 5$ after farrowing, ac- cording to the biological litter. Mortality at d 30 was calculated as (TNB - LS30)/TNB, also according to the biological litter. Average BirthWt was calculated by taking the mean weight of the number of live piglets at processing. Classification of death was not given in this dataset and is, therefore, not considered in this analysis.

\section{Statistical Analysis}

Variance components were estimated using AIREMLF90 in the BLUPF90 family of programs (Misztal et al., 2002). All analyses were completed with either single or bivariate trait models. An animal model was used in which all traits, except NW, were treated as a trait of the biological dam. The statistical model used to describe the data was

$$
\mathbf{y}=\mathbf{X b}+\mathbf{Z d}+\mathbf{W p e}+\mathbf{e},
$$

where $\mathbf{y}$ is the vector of observations (litter size, mortality, and BirthWt); $\mathbf{b}$ is a vector of fixed effects including farm, year-season, parity, and NBA fit as a covariate for BirthWt; $\mathbf{d}$ is a vector of additive genetic effects of the dam; pe is a vector of permanent environmental effects of the dam; $\mathbf{e}$ is a vector of random residuals; and $\mathbf{X}, \mathbf{Z}$, and $\mathbf{W}$ are coefficient matrices associating $\mathbf{b}, \mathbf{d}$, and pe with $\mathbf{y}$, respectively. Assumptions for random effects were

$$
\left[\begin{array}{c}
\mathbf{d} \\
\mathbf{p e} \\
\mathbf{e}
\end{array}\right] \sim \mathrm{N}\left(\left[\begin{array}{l}
0 \\
0 \\
0
\end{array}\right],\left[\begin{array}{ccc}
\mathbf{A} \otimes \boldsymbol{\Sigma}_{\mathbf{d}} & 0 & 0 \\
0 & \mathbf{I}_{\mathrm{pe}} \otimes \boldsymbol{\Sigma}_{\mathbf{p e}} & 0 \\
0 & 0 & \mathbf{I}_{\mathbf{e}} \otimes \boldsymbol{\Sigma}_{\mathbf{e}}
\end{array}\right]\right)
$$

where $\Sigma_{\mathbf{d}}, \Sigma_{\mathbf{p e}}$, and $\boldsymbol{\Sigma}_{\mathbf{e}}$ are covariance matrices for additive genetic effects of the dam, permanent environmental effects of the dam, and residual effects, respectively; $\mathbf{I}_{\mathbf{p e}}$ is an identity matrix with dimensions equal to the number of parities; $\mathbf{I}_{\mathbf{e}}$ is an identity matrix equal to the number of observations; and $\mathbf{A}$ is the additive genetic relationship matrix. The pedigree was traced back 3 generations for both the LW and LR breeds. Descriptive statistics of the data are shown in Table 1, including the number of litters, sows, year-season classes, and farms. Parities 4 and 5 were grouped together for a total of 4 parity classes.

Phenotypic variation $\left(\sigma_{p}^{2}\right)$ was defined as $\sigma_{p}^{2}=\sigma_{d}^{2}+\sigma_{p e}^{2}+\sigma_{e}^{2}$, where $\sigma_{d}^{2}$ is the variance of sow additive genetic effects, $\sigma_{p e}^{2}$ is the variance of permanent environmental effects, and $\sigma_{e}^{2}$ is the residual variance. All traits were assigned to litters and therefore traits of the sow; thus, $\mathrm{h}^{2}$ was defined as $\mathrm{h}^{2}=\sigma_{d}^{2} / \sigma_{p}^{2}$.

Standard errors for $\mathrm{h}^{2}$ estimates were calculated using an equation from Tsuruta (2015). 


$$
\begin{aligned}
& \mathrm{SE}^{2}\left(\mathrm{~h}^{2}\right)=\left(\frac{\mathrm{h}^{2}\left(1-\mathrm{h}^{2}\right)}{a}-\frac{\mathrm{h}^{2}\left(\mathrm{~h}^{2}\right)}{a}-\frac{\mathrm{h}^{2}\left(\mathrm{~h}^{2}\right)}{a}\right) \times \\
& \left(\begin{array}{ccc}
\operatorname{var}(a) & \operatorname{cov}(a, p e) & \operatorname{cov}(a, e) \\
\operatorname{cov}(p e, a) & \operatorname{var}(p e) & \operatorname{cov}(p e, e) \\
\operatorname{cov}(e, a) & \operatorname{cov}(e, p e) & \operatorname{var}(e)
\end{array}\right) \times \\
& \left(\begin{array}{c}
\frac{\mathrm{h}^{2}\left(1-\mathrm{h}^{2}\right)}{a} \\
-\frac{\mathrm{h}^{2}\left(\mathrm{~h}^{2}\right)}{a} \\
-\frac{\mathrm{h}^{2}\left(\mathrm{~h}^{2}\right)}{a}
\end{array}\right)
\end{aligned}
$$

where $a$ is the additive genetic variance, $p e$ is the permanent environmental variance, and $e$ is the residual variance. The leading row vector and following column vector are partial derivatives solved by taking the partial derivative of $\mathrm{h}^{2}$ with respected to $a$, pe, and $e$, respectively. Components of the internal matrix were taken from the inverse of the average information matrix output by AIREMLF90.

Standard errors for genetic correlations were calculated using an equation from Tsuruta (2015).

$$
\begin{aligned}
& r=\frac{x_{12}}{\sqrt{x_{1} x_{2}}} \\
& \mathrm{SE}^{2}(r)=\left(\begin{array}{lll}
-\frac{r}{2 x_{1}} & -\frac{r}{2 x_{2}} & \frac{r}{x_{12}}
\end{array}\right) \times \\
& \left(\begin{array}{ccc}
\operatorname{var}\left(x_{1}\right) & \operatorname{cov}\left(x_{1}, x_{2}\right) & \operatorname{cov}\left(x_{1}, x_{12}\right) \\
\operatorname{cov}\left(x_{2}, x_{1}\right) & \operatorname{var}\left(x_{2}\right) & \operatorname{cov}\left(x_{2}, x_{12}\right) \\
\operatorname{cov}\left(x_{12}, x_{1}\right) & \operatorname{cov}\left(x_{12}, x_{2}\right) & \operatorname{var}\left(x_{12}\right)
\end{array}\right) \times \\
& \left(\begin{array}{c}
-\frac{r}{2 x_{1}} \\
-\frac{r}{2 x_{2}} \\
\frac{r}{x_{12}}
\end{array}\right)
\end{aligned}
$$

where $r$ is the genetic correlation between traits 1 and $2, x_{1}$ is the genetic variance of trait $1 ; x_{2}$ is the genetic variance of trait 2 , and $x_{12}$ is the genetic covariance between trait 1 and 2. Components for the matrix were also taken from the inverse of the average information matrix output by AIREMLF90.

Correlated response to selection for LS30 was calculated for each day with the equation

$$
C R_{\mathrm{LS} 30}=i \mathrm{~h}_{\mathrm{LS}} \mathrm{h}_{\mathrm{LS} 30} r_{a} \sigma_{\mathrm{LS} 30}
$$

where $i$ is the intensity of selection, assumed to be 1.4 to correspond with the top $20 \%$ selected each genera-
Table 1. Number of litters, sows, year-seasons, and farms for each breed

\begin{tabular}{lcccc}
\hline \hline Breed & Litters & Sows & YS $^{1}$ & Farms $^{2}$ \\
\hline Large White & 8,257 & 4,849 & 16 & 3 \\
Landrace & 6,928 & 4,443 & 16 & 3 \\
\hline
\end{tabular}

${ }^{1}$ Year-season. Four full years of data were analyzed that included 4 seasons per year.

${ }^{2}$ There were 4 farms total. Two of the farms contained both Large White and Landrace breeds. Of the 2 remaining farms, 1 had Large White and 1 had Landrace only.

tion; $\mathrm{h}$ is the square root of $\mathrm{h}^{2} ; r_{a}$ is the genetic correlation between litter size (TNB, NBA, and LS2 to LS29) and LS30; and $\sigma_{\mathrm{LS} 30}$ is the phenotypic standard deviation of LS30. The $C R_{\mathrm{LS} 30}$ for each day was then standardized to the response to selection in LS30 $\left(R_{\mathrm{LS} 30}\right)$ for each breed by dividing the correlated response by the response to selection in LS30 and multiplying by 100 to calculate a percentage.

\section{RESULTS}

Unadjusted phenotypic means and standard deviations for TNB, NBA, LS2, LS5, LS10, LS30, LSW, NW, MortD30, and BirthWt are shown in Table 2. Large White had a greater phenotypic litter size for all litter size traits as well as larger SD except for NW. Means for

\begin{tabular}{|c|c|c|c|c|}
\hline \multirow[b]{2}{*}{ Trait $^{1}$} & \multicolumn{2}{|c|}{ Large White } & \multicolumn{2}{|c|}{ Landrace } \\
\hline & Mean & SD & Mean & SD \\
\hline TNB & 12.77 & 3.64 & 11.95 & 3.31 \\
\hline NBA & 11.47 & 3.48 & 10.86 & 3.07 \\
\hline LS2 & 10.56 & 3.29 & 10.16 & 2.87 \\
\hline LS5 & 10.01 & 3.09 & 9.64 & 2.70 \\
\hline LS10 & 9.66 & 3.00 & 9.18 & 2.67 \\
\hline LS30 & 9.17 & 2.94 & 8.61 & 2.68 \\
\hline $\mathrm{LSW}^{2}$ & 9.31 & 2.95 & 8.78 & 2.66 \\
\hline $\mathrm{NW}^{2}$ & 9.22 & 2.93 & 8.55 & 2.73 \\
\hline MortD30 & 0.26 & 0.18 & 0.25 & 0.19 \\
\hline BirthWt ${ }^{3}, \mathrm{~kg}$ & 1.50 & 0.25 & 1.56 & 0.25 \\
\hline
\end{tabular}
LW ranged from 9.17 to 12.77 for litter size traits, while LR ranged from 8.55 to 11.95 . Standard deviations decreased from TNB through NW and ranged from 2.93 to 3.64 in litter size traits for $\mathrm{LW}$ and 2.66 to 3.31 in LR.

Table 2. Mean and SD for litter size traits, mortality, and birth weight in 8,257 Large White and 6,928 Landrace litters

${ }^{1}$ Traits included total number born (TNB), number born alive (NBA), litter size at d 2, 5, 10, and 30 (LS2, LS5, LS10, and LS30), litter size at weaning (LSW), number weaned (NW), mortality at d 30 (MortD30), and average birth weight (BirthWt).

${ }^{2} \mathrm{NW}$ was recorded as how many piglets were present in the litter at the time of weaning. This would include any piglets cross-fostered onto that litter and exclude those cross-fostered off. LSW is calculated as the number of piglets alive at weaning according to the biological litter.

${ }^{3}$ BirthWt was the average of piglets alive at processing. 


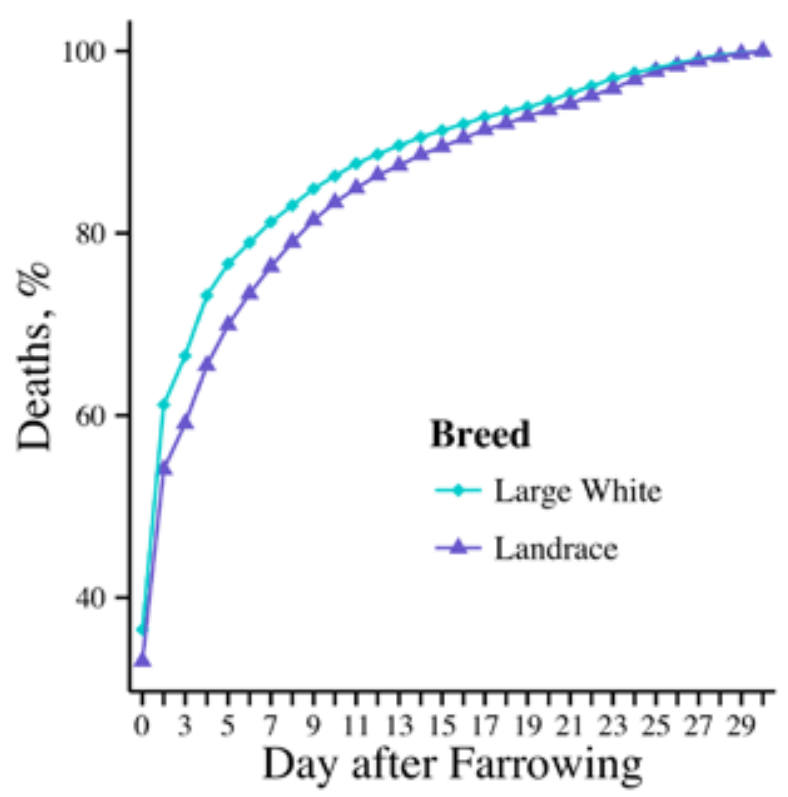

Figure 1. Percentage of deaths calculated as a ratio of cumulative deaths out of the total number of deaths at $\mathrm{d} 30$. Starting at $\mathrm{d} 0$ (stillborns) and $\mathrm{d} 2$ to 30 . Piglet processing was done within $48 \mathrm{~h}$; therefore, $\mathrm{d} 1$ could not be distinguished from $\mathrm{d} 2$.

Mortality at d 30 was $1 \%$ greater for LW than LR with a slightly lower SD. Average BirthWt was $0.06 \mathrm{~kg}$ higher for LR with the same SD. The regression of BirthWt on TNB was $-0.034 \mathrm{~kg}$ in LW and $-0.033 \mathrm{~kg}$ in LR.

The cumulative percentage of deaths through $\mathrm{d}$ 30 is displayed in Fig. 1. Fewer than $40 \%$ of deaths happened at farrowing (d 0, stillborns). Within $9 \mathrm{~d}$ of birth, both breeds exceeded $80 \%$ of their respective preweaning mortalities at $\mathrm{d} 30$. Large White sows had a greater percentage of piglet deaths at farrowing and throughout lactation until converging with LR at d 25 . The difference was greatest for $\mathrm{d} 2$ to 5 . This figure shows that LR sows had proportionately more piglet deaths later in lactation than those of LW sows.

Additive genetic, permanent environmental, total variance, and $\mathrm{h}^{2}$ for TNB, NBA, and LS2 to LS30 are plotted in Fig. 2. Additive genetic variances were greatest for TNB and NBA, and decreased until $\mathrm{d} 7$ for LR and d 14 for LW and then increased slightly thereafter. Additive genetic variances were higher for LW from TNB to LS30, including a sizeable difference in NBA. In general, permanent environmental variances decreased as lactation progressed. There were significant differences between the breeds at $\mathrm{d} 2$ to 7 . Total variances declined within the first $10 \mathrm{~d}$ of lactation and decreased only slightly thereafter. Total variances were greater for the LW breed across litter size traits. Residual variances (not shown) followed a very similar trend to total variances, ranging from 7.0 to 10.8 in LW and 5.7 to 9.0 in LR. Heritability for litter size traits increased overall from TNB to LS30 for the 2 breeds. The estimates were minimized at LS3 for LW and NBA for LR. Heritability estimates tended to be slightly higher for the LR breed. The main differences between breeds happened between $\mathrm{d} 2$ and 12 and after $\mathrm{d} 22$, although not significantly different given the SE.

Genetic correlations between LS30 and TNB, NBA, and LS2 to LS29 are plotted in Fig. 3. Correlations started out moderate, below 0.75 for TNB in both breeds, and then increased before plateauing around $\mathrm{d} 4$ for LW and $\mathrm{d} 7$ for LR. The genetic correlations for each previous trait with LS30 increased more rapidly after parturition for LW than for LR. Large White reached a genetic correlation of 0.95 by d 4 , while LR reached 0.95 at $\mathrm{d} 8$.

Estimated variance components for litter traits from LW and LR are shown in Table 3. In both breeds, NW had the lowest genetic variance and $\mathrm{h}^{2}$ among the litter size traits. Phenotypic variance decreased steadily and then remained relatively constant after LS5 for each breed in litter size traits. Heritability estimates for litter size traits and MortD30 ranged from 0.09 to 0.13 in LW and 0.07 to 0.12 in LR. Heritability estimates for BirthWt were 0.24 for LW and 0.26 for LR. Standard errors for $\mathrm{h}^{2}$ estimates were less than or equal to 0.02 for all traits, making all traits statistically greater than zero.

Genetic correlations among litter size traits, MortD30, and BirthWt are displayed in Table 4. Genetic correlations among weaning traits LS30, LSW, and NW ranged from 0.97 to 1.00 . In LW, an unfavorable correlation of 0.23 between TNB and MortD30 was observed, but was -0.64 between LS30 and MortD30; in LR, the correlations were 0.10 for TNB and MortD30 and -0.61 for LS30 and MortD30. Average BirthWt showed a similar trend. The genetic correlations were -0.46 between TNB and BirthWt and -0.15 between LS30 and BirthWt in LW pigs. In LR, the correlations were -0.44 between TNB and BirthWt and -0.25 between LS30 and BirthWt. Although neither correlation was favorable (i.e., positive) by $\mathrm{d} 30$, they were not as negative. Litter size at d 5 and NW had genetic correlations of 0.96 and 0.85 , while NW and LS10 had even stronger 0.98 and 0.97 correlations for LW and LR, respectively. Genetic correlations between TNB and NW were only moderate at 0.55 for both LW and LR. BirthWt and MortD30 had low but favorable genetic correlations of -0.14 for LW and -0.13 for LR.

Figure 4 shows the correlated response in LS30 when selecting for TNB, NBA, or LS2 to LS29. Large changes can be seen up until LS4, after which smaller increments were observed. Among litter size traits, the largest difference was between LS3 and LS4. Ninety percent of the response in LS30 was captured at $\mathrm{d} 8$ in both LW and LR breeds. Correlated responses did not plateau as much by d 10 compared to the genetic correlations (Fig. 3). 


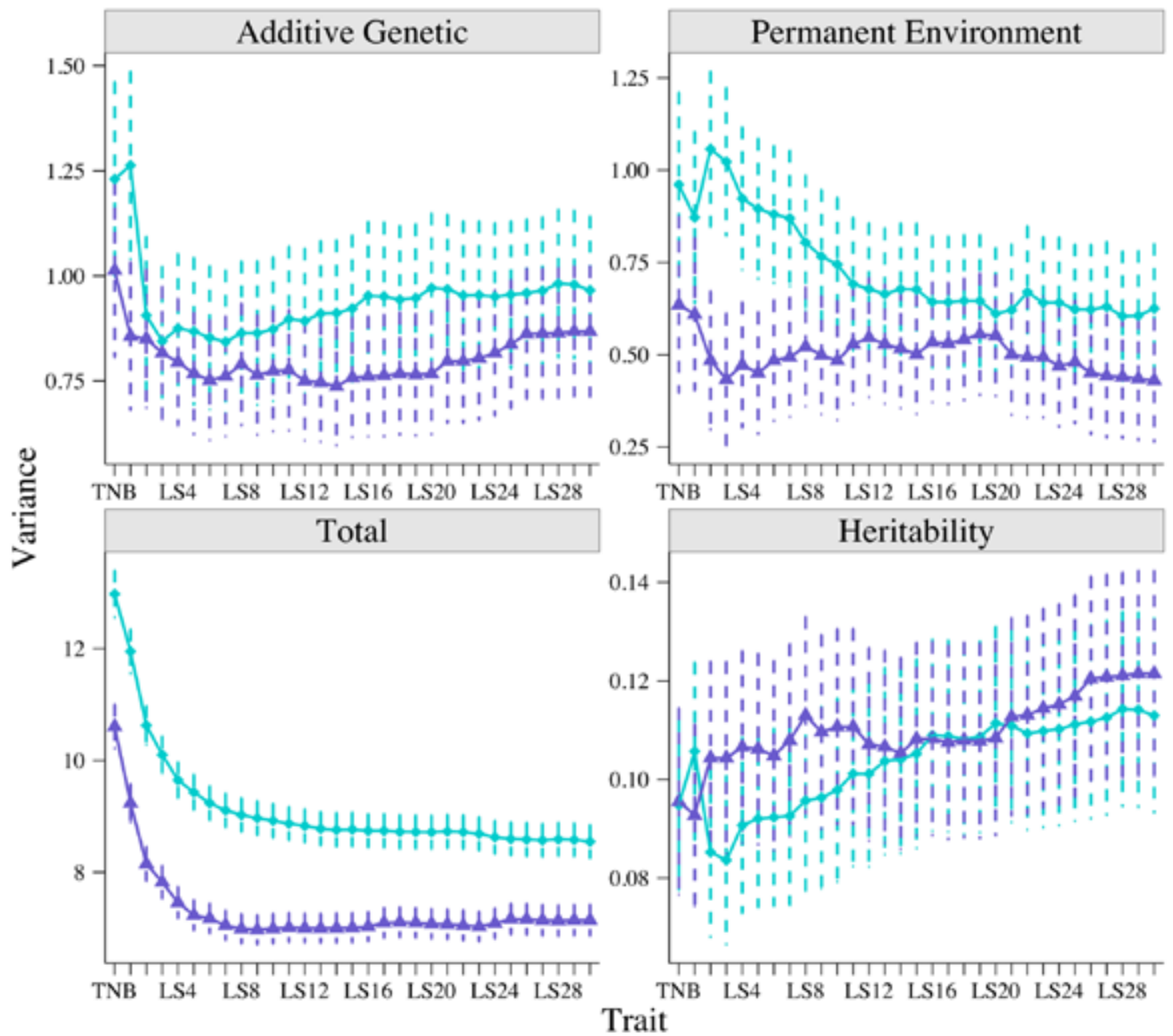

\section{Breed $\rightarrow$ Large White $\leadsto$ Landrace}

Figure 2. Genetic, permanent environmental, and total variances for total number born (TNB), number born alive (NBA), and litter size at $\mathrm{d} 2$ to 30 (LS2 to LS30) with the respective $\mathrm{h}^{2}$. Y-axes are independent of each other.

\section{DISCUSSION}

\section{Selecting the Optimum Day or Trait for Selection}

The main objective of the present study was to determine which day (litter size trait) might be used to obtain the optimal genetic progress in the number of viable weaned pigs per sow and decrease in preweaning mortality. Plotting variances and genetic correlations across days was done to try to determine this objectively rather than simply examining a histogram or percentage of deaths figure. Small fluctuations in point estimates for each trait were expected and observed, but overall the trends were fairly smooth. Selection intensity was held constant and given only slight variation in $\mathrm{h}^{2}$ estimates among traits; most of the trend was explained by the genetic correlations between the traits and LS30. No maxima were observed before $\mathrm{d} 30$, which was an

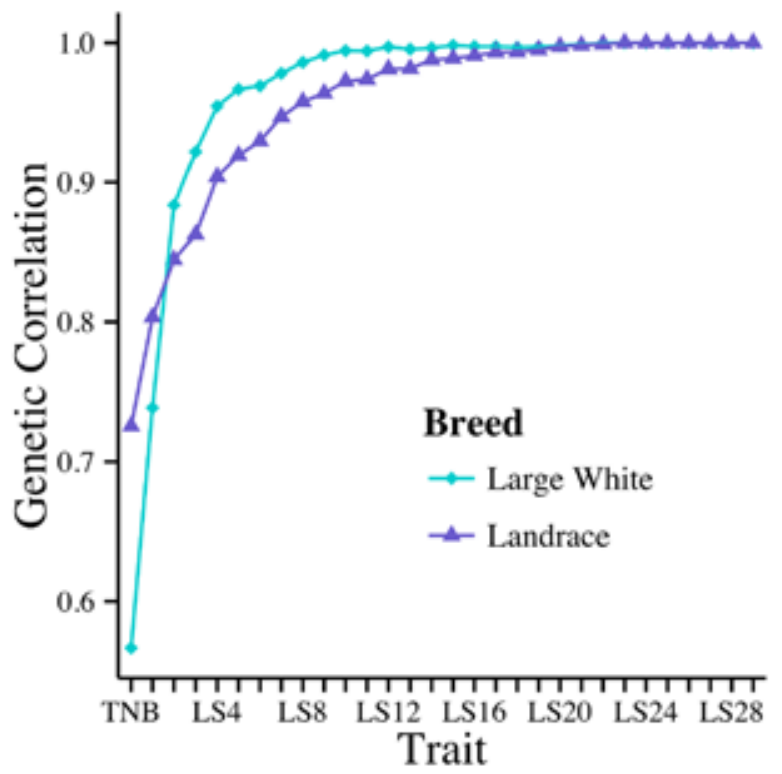

Figure 3. Genetic correlation between litter size at d 30 (LS30) and total number born (TNB), number born alive (NBA), and litter size at d 2 to 29 (LS2 to LS29). 
Table 3. Additive genetic variance $\left(\sigma_{d}^{2}\right)$, permanent environmental variance $\left(\sigma_{p e}^{2}\right)$, total variance $\left(\sigma_{p}^{2}\right)$, and $\mathrm{h}^{2}$ with SE for litter size traits, mortality, and birth weight in 8,257 Large White and 6,928 Landrace litters

\begin{tabular}{|c|c|c|c|c|c|c|c|c|c|c|}
\hline \multirow[b]{2}{*}{ Trait $^{1}$} & \multicolumn{4}{|c|}{ Large White } & \multirow[b]{2}{*}{$\mathrm{SE}\left(\mathrm{h}^{2}\right)$} & \multicolumn{4}{|c|}{ Landrace } & \multirow[b]{2}{*}{$\mathrm{SE}\left(\mathrm{h}^{2}\right)$} \\
\hline & $\sigma_{d}^{2}$ & $\sigma_{p e}^{2}$ & $\sigma_{p}^{2}$ & $\mathrm{~h}^{2}$ & & $\sigma_{d}^{2}$ & $\sigma_{p e}^{2}$ & $\sigma_{p}^{2}$ & $\mathrm{~h}^{2}$ & \\
\hline TNB & 1.240 & 0.971 & 13.039 & 0.10 & 0.02 & 1.015 & 0.701 & 10.677 & 0.10 & 0.02 \\
\hline NBA & 1.257 & 0.873 & 11.996 & 0.10 & 0.02 & 0.870 & 0.637 & 9.296 & 0.09 & 0.02 \\
\hline LS2 & 0.938 & 1.041 & 10.648 & 0.095 & 0.02 & 0.861 & 0.504 & 8.219 & 0.10 & 0.02 \\
\hline LS5 & 0.901 & 0.864 & 9.444 & 0.10 & 0.02 & 0.774 & 0.462 & 7.305 & 0.11 & 0.02 \\
\hline LS10 & 0.888 & 0.729 & 8.949 & 0.10 & 0.02 & 0.777 & 0.490 & 7.029 & 0.11 & 0.02 \\
\hline LS30 & 0.986 & 0.611 & 8.592 & 0.11 & 0.02 & 0.860 & 0.424 & 7.156 & 0.12 & 0.02 \\
\hline $\mathrm{LSW}^{2}$ & 0.926 & 0.640 & 8.652 & 0.11 & 0.02 & 0.831 & 0.494 & 7.022 & 0.12 & 0.02 \\
\hline $\mathrm{NW}^{3}$ & 0.802 & 0.630 & 8.513 & 0.09 & 0.02 & 0.610 & 0.660 & 7.389 & 0.08 & 0.02 \\
\hline MortD30 4 & 0.004 & 0.002 & 0.031 & 0.13 & 0.02 & 0.002 & 0.001 & 0.032 & 0.07 & 0.02 \\
\hline BirthWt ${ }^{5}, \mathrm{~kg}$ & 0.013 & 0.005 & 0.056 & 0.24 & 0.02 & 0.015 & 0.002 & 0.057 & 0.26 & 0.02 \\
\hline
\end{tabular}

${ }^{1}$ Traits included total number born (TNB), number born alive (NBA), litter size at d 2, 5, 10, and 30 (LS2, LS5, LS10, and LS30), litter size at weaning (LSW), number weaned (NW), mortality at d 30 (MortD30), and average birth weight (BirthWt).

${ }^{2} \mathrm{LSW}$ is calculated as the number of piglets alive at weaning according to the biological litter.

${ }^{3} \mathrm{NW}$ was recorded as how many piglets were present in the litter at the time of weaning. This would include any piglets cross-fostered onto that litter and exclude those cross-fostered off.

${ }^{4}$ Mortality at d 30 was assigned to biological litters and calculated as (TNB - LS30)/TNB.

${ }^{5}$ BirthWt was the average of piglets alive at processing (within $48 \mathrm{~h}$ ).

Table 4. Genetic correlations for litter size traits, mortality, and birth weight in 8,257 Large White litters (above diagonal) and 6,928 Landrace litters (below diagonal)

\begin{tabular}{|c|c|c|c|c|c|c|c|c|c|c|}
\hline Trait $^{1}$ & TNB & NBA & LS2 & LS5 & LS10 & LS30 & LSW & NW & MortD30 & BirthWt \\
\hline TNB & & $\begin{array}{c}0.91 \\
(0.02)\end{array}$ & $\begin{array}{c}0.81 \\
(0.05)\end{array}$ & $\begin{array}{c}0.73 \\
(0.06)\end{array}$ & $\begin{array}{c}0.66 \\
(0.07)\end{array}$ & $\begin{array}{c}0.57 \\
(0.08)\end{array}$ & $\begin{array}{c}0.61 \\
(0.08)\end{array}$ & $\begin{array}{c}0.55 \\
(0.10)\end{array}$ & $\begin{array}{c}0.23 \\
(0.12)\end{array}$ & $\begin{array}{c}-0.46 \\
(0.08)\end{array}$ \\
\hline NBA & $\begin{array}{c}0.89 \\
(0.03)\end{array}$ & & $\begin{array}{c}0.96 \\
(0.01)\end{array}$ & $\begin{array}{c}0.87 \\
(0.03)\end{array}$ & $\begin{array}{c}0.80 \\
(0.05)\end{array}$ & $\begin{array}{c}0.74 \\
(0.06)\end{array}$ & $\begin{array}{c}0.77 \\
(0.05)\end{array}$ & $\begin{array}{c}0.74 \\
(0.07)\end{array}$ & $\begin{array}{c}-0.04 \\
(0.12)\end{array}$ & $\begin{array}{c}-0.44 \\
(0.08)\end{array}$ \\
\hline LS2 & $\begin{array}{c}0.87 \\
(0.04)\end{array}$ & $\begin{array}{c}0.98 \\
(0.01)\end{array}$ & & $\begin{array}{c}0.97 \\
(0.01)\end{array}$ & $\begin{array}{c}0.93 \\
(0.02)\end{array}$ & $\begin{array}{c}0.88 \\
(0.03)\end{array}$ & $\begin{array}{c}0.90 \\
(0.03)\end{array}$ & $\begin{array}{c}0.88 \\
(0.04)\end{array}$ & $\begin{array}{c}-0.34 \\
(0.12)\end{array}$ & $\begin{array}{c}-0.27 \\
(0.10)\end{array}$ \\
\hline LS5 & $\begin{array}{c}0.85 \\
(0.04)\end{array}$ & $\begin{array}{c}0.93 \\
(0.02)\end{array}$ & $\begin{array}{c}0.96 \\
(0.01)\end{array}$ & & $\begin{array}{c}0.99 \\
(0.00)\end{array}$ & $\begin{array}{c}0.97 \\
(0.01)\end{array}$ & $\begin{array}{c}0.98 \\
(0.01)\end{array}$ & $\begin{array}{c}0.96 \\
(0.02)\end{array}$ & $\begin{array}{c}-0.48 \\
(0.10)\end{array}$ & $\begin{array}{c}-0.20 \\
(0.10)\end{array}$ \\
\hline LS10 & $\begin{array}{c}0.80 \\
(0.05)\end{array}$ & $\begin{array}{c}0.88 \\
(0.04)\end{array}$ & $\begin{array}{c}0.90 \\
(0.03)\end{array}$ & $\begin{array}{c}0.98 \\
(0.01)\end{array}$ & & $\begin{array}{c}0.99 \\
(0.00)\end{array}$ & $\begin{array}{c}1.00 \\
(0.00)\end{array}$ & $\begin{array}{c}0.98 \\
(0.01)\end{array}$ & $\begin{array}{c}-0.54 \\
(0.10)\end{array}$ & $\begin{array}{c}-0.19 \\
(0.10)\end{array}$ \\
\hline LS30 & $\begin{array}{c}0.73 \\
(0.07)\end{array}$ & $\begin{array}{c}0.80 \\
(0.05)\end{array}$ & $\begin{array}{c}0.84 \\
(0.04)\end{array}$ & $\begin{array}{c}0.92 \\
(0.02)\end{array}$ & $\begin{array}{c}0.98 \\
(0.00)\end{array}$ & & $\begin{array}{c}1.00 \\
(0.00)\end{array}$ & $\begin{array}{c}0.99 \\
(0.01)\end{array}$ & $\begin{array}{c}-0.64 \\
(0.08)\end{array}$ & $\begin{array}{c}-0.15 \\
(0.10)\end{array}$ \\
\hline $\mathrm{LSW}^{2}$ & $\begin{array}{c}0.75 \\
(0.06)\end{array}$ & $\begin{array}{c}0.83 \\
(0.05)\end{array}$ & $\begin{array}{c}0.86 \\
(0.04)\end{array}$ & $\begin{array}{c}0.93 \\
(0.02)\end{array}$ & $\begin{array}{c}0.98 \\
(0.01)\end{array}$ & $\begin{array}{c}1.00 \\
(0.00)\end{array}$ & & $\begin{array}{c}0.98 \\
(0.01)\end{array}$ & $\begin{array}{c}-0.60 \\
(0.08)\end{array}$ & $\begin{array}{c}-0.15 \\
(0.10)\end{array}$ \\
\hline $\mathrm{NW}^{3}$ & $\begin{array}{c}0.55 \\
(0.11)\end{array}$ & $\begin{array}{c}0.63 \\
(0.10)\end{array}$ & $\begin{array}{c}0.76 \\
(0.08)\end{array}$ & $\begin{array}{c}0.85 \\
(0.06)\end{array}$ & $\begin{array}{c}0.97 \\
(0.03)\end{array}$ & $0.97^{4}$ & $0.97^{4}$ & & $\begin{array}{c}-0.58 \\
(0.09)\end{array}$ & $\begin{array}{c}-0.17 \\
(0.10)\end{array}$ \\
\hline MortD30 & $\begin{array}{c}0.10 \\
(0.14)\end{array}$ & $\begin{array}{c}-0.14 \\
(0.15)\end{array}$ & $\begin{array}{c}-0.25 \\
(0.14)\end{array}$ & $\begin{array}{c}-0.35 \\
(0.14)\end{array}$ & $\begin{array}{c}-0.49 \\
(0.12)\end{array}$ & $\begin{array}{c}-0.61 \\
(0.10)\end{array}$ & $\begin{array}{c}-0.58 \\
(0.10)\end{array}$ & $\begin{array}{c}-0.70 \\
(0.10)\end{array}$ & & $\begin{array}{c}-0.14 \\
(0.09)\end{array}$ \\
\hline BirthWt ${ }^{6}$ & $\begin{array}{c}-0.44 \\
(0.09)\end{array}$ & $\begin{array}{c}-0.52 \\
(0.08)\end{array}$ & $\begin{array}{c}-0.39 \\
(0.09)\end{array}$ & $\begin{array}{c}-0.34 \\
(0.09)\end{array}$ & $\begin{array}{c}-0.30 \\
(0.09)\end{array}$ & $\begin{array}{c}-0.25 \\
(0.09)\end{array}$ & $\begin{array}{c}-0.24 \\
(0.09)\end{array}$ & $\begin{array}{c}-0.22 \\
(0.11)\end{array}$ & $\begin{array}{c}-0.13 \\
(0.11)\end{array}$ & \\
\hline
\end{tabular}

${ }^{1}$ Traits included total number born (TNB), number born alive (NBA), litter size at d 2, 5, 10, and 30 (LS2, LS5, LS10, and LS30), litter size at weaning (LSW), number weaned (NW), mortality at d 30 (MortD30), and average birth weight (BirthWt).

${ }^{2} \mathrm{LSW}$ is calculated as the number of piglets alive at weaning according to the biological litter.

${ }^{3} \mathrm{NW}$ was recorded as how many piglets were present in the litter at the time of weaning. This would include any piglets cross-fostered onto that litter and exclude those cross-fostered off.

${ }^{4}$ Standard errors were not obtained due to AIREML failing to converge. Instead, REML was used to calculate the genetic correlation and estimates of the SE we were not obtainable.

${ }^{5}$ Mortality at d 30 was assigned to biological litters and calculated as (TNB - LS30)/TNB.

${ }^{6} \mathrm{BirthWt}$ was the average of piglets alive at processing (within $48 \mathrm{~h}$ ). 


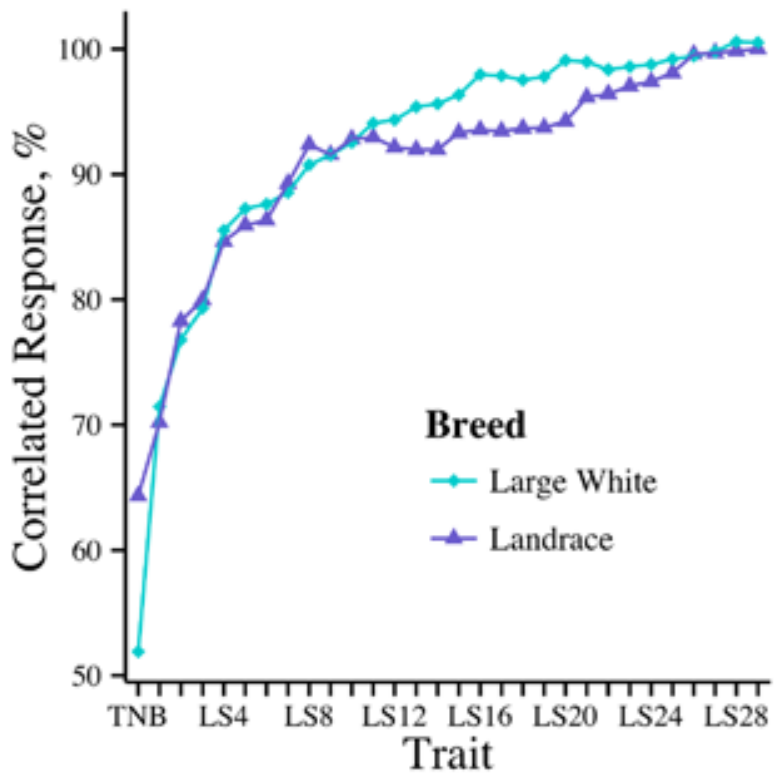

Figure 4. Correlated response to selection in litter size at d 30 (LS30) for total number born (TNB), number born alive (NBA), and litter size at d 2 to 29 (LS2 to LS29).

important part of the objective; therefore LSW or LS30 should be considered for selection. However, problems exist with increasing nurse dam effects and additive genetic effects of the piglet. The piglets' direct additive genetic effects have more of an influence on survival in later days. Based on the results from the present study, LSW or LS30 would result in the most progress for piglets weaned. A compromise may be using LS10 because the genetic correlations and correlated response in LS30 plateaued at this point and would limit the effects of the nurse dam and the direct additive genetic effects of the piglet at a later day such as weaning or $d$ 30. It was also observed that LS10 and LSW had a very high genetic correlation of 1.00 in LW and 0.98 in LR.

\section{Modeling Litter Size Traits}

A direct-maternal model could not be fit because the piglet dataset did not include records for all fully formed piglets at birth. Only a subset of the piglets were weighed and recorded for those alive at processing (within $48 \mathrm{~h}$ ). The litter size traits of interest, however, are modeled at the sow level because they are by definition a trait of the sow. Bidanel (2011) concluded that the largest proportion of the genetic variation is due to the dam for litter size traits, although the direct additive genetic effect of the piglet does increase throughout lactation (Su et al., 2008). Knol et al. (2002b) stated that using a direct piglet/maternal/nurse sow model would require precise recording of stillbirths and cross-fostering, a large dataset, and powerful statistical analyses. A common objection to litter size traits is the ignoring of the nurse dam in the model; however, a relatively large amount of cross-fostering would be needed to estimate such an effect (Knol et al., 2002a). In the current data set, cross-fostering was relatively low at 4.9 and $8.3 \%$ for LW and LR, respectively. Moreover, including nurse sow effects in the model gave erratic results as a whole (Knol et al., 2002a). Running large models can run the risk of overparameterization. For example, a model that includes direct, maternal, and nurse sow effects would include 8 variance components (covariances plus litter and residual; see Knol et al., 2002a). If nurse sow were to be added to the model, other effects, such as nurse sow parity, may need to be included to effectively model the nurse sow effect. Nielsen et al. (2013) suggested that a generalized linear mixed model for mortality might have problems with overdispersion. A pilot study conducted by Su et al. (2007) found that the nurse sow had a small influence on piglet survival in the first $5 \mathrm{~d}$ after farrowing. One alternative method would be to integrate an LS trait in the maternal lines, while selecting for direct piglet survival as a binary trait in the paternal lines. The maternal component for survival would not be realized in the terminal commercial animal from the paternal line, but the direct additive effects would be expressed.

Litter size at d 5 selection over 7 yr showed a genetic improvement of 1.3 and 1.9 piglets per litter for TNB, 1.7 and 2.2 piglets per litter for LS5, and 4.7 and $5.9 \%$ for mortality at d 5 in LR and LW breeds, respectively (Nielsen et al., 2013). Results from Nielsen et al. (2013) showed that even though litter size traits ignore the nurse dam and direct additive genetic effects of the piglet, selection was successful in reducing mortality and increasing litter size at birth. A different model for piglet survival based on the binary observation of piglet survival has been implemented in the breeding program of TOPIGS. In $10 \mathrm{yr}$, genetic trends reduced piglet mortality by approximately $0.5 \%$ while litter size has increased by 1.4 pigs (Merks et al., 2012). These results compared to Danish results are not directly comparable because Nielsen et al. (2013) published litter size and mortality at $\mathrm{d} 5$. Other factors are also unknown, such as selection intensity and proportion of the aggregate genotype. The debate on modeling piglet survival will continue, but it seems possible to make genetic improvement using either model.

\section{Variance Components}

The current analysis was extended to $\mathrm{d} 30$ to show variance components up to and past weaning. This was done to try to include the early nursery mortalities in a total measure of piglet mortality. Piglets may be counted as weaned and fail to thrive early in the nursery period. Although not directly responsible for 
the piglet's death, the sow could still have a residual effect on the piglet early in the nursery.

Trends in variances for litter size traits (Fig. 2) are in agreement with a previous study on LS5 (Su et al., 2007). Heritability estimates increased on a positive, linear trend from TNB to LS30. Su et al. (2007) showed $\mathrm{h}^{2}$ for the sow component increased from 0.066 for TNB to 0.090 for LSW in LR and 0.053 to 0.065 in LW. In the present study, $\mathrm{h}^{2}$ was slightly higher, which may have been caused by a different population structure and a less complex model. Su et al. (2007) included service-sire additive genetic and permanent environmental effects. Heritability estimates for TNB and NBA reported in this study were close to reported literature values at approximately 0.10 (Bidanel, 2011). Previous reported estimates for LS5 range from 0.07 to 0.10 (Su et al., 2007; Nielsen et al., 2013). Results from the present study are consistent with these estimates. Mortality at $\mathrm{d} 30$ had a slightly higher $\mathrm{h}^{2}$ than literature values of 0.07 for farrowing survival and 0.05 for birth to weaning survival (Bidanel 2011), of which MortD30 is a combination of these 2 traits. Nielsen et al. (2013) reported $\mathrm{h}^{2}$ of 0.09 and 0.10 for mortality at $\mathrm{d} 5$ for LR and LW breeds, respectively. The estimates from the present study were close to those reported by Nielsen et al. (2013), although not directly comparable, as the current estimates were from mortality at $\mathrm{d} 30$ instead of $\mathrm{d} 5$.

Heritability for BirthWt for both breeds was comparable to the 0.24 reported by Bidanel (2011). Birth weight in this study was considered a trait of the sow. Some authors have chosen to split direct and maternal effects to effectively split genetic components. Direct and maternal $\mathrm{h}^{2}$ estimates averaged 0.06 and 0.19 (Roehe, 1999; Knol et al., 2002a; Grandinson et al., 2002; Arango et al., 2006; Su et al., 2008). The genetic correlation between direct and maternal components averaged -0.19 (Roehe, 1999; Knol et al., 2002a; Arango et al., 2006; Su et al., 2008). This unfavorable relationship between direct and maternal components would mean that direct selection for BirthWt would have an antagonistic relationship with the maternal BirthWt component, and both would have to be included into the aggregate genotype for selection.

An interesting result was the change in additive genetic variances over time. The additive genetic variance was minimized within $10 \mathrm{~d}$, which is unfavorable, and then increased slightly thereafter. Given the SE of these variances ( 0.14 to 0.20 in $\mathrm{LW}$ and 0.13 to 0.18 in LR), the increase would not be considered statistically significant but it would be considered noteworthy. It is not clear what caused the subsequent increase. One plausible explanation may be that the direct additive genetic effect of the piglet (not accounted for in the model) was partitioned into the maternal additive genetic variance instead of the residual during later days, as the direct additive variance is expected to increase with age ( $\mathrm{Su}$ et al., 2008). Further investigation into this issue may need to be addressed in the future along with the increased effects of the nurse dam later in lactation.

\section{Genetic Correlations}

The genetic correlation between LS5 and LSW was slightly lower than the 0.995 estimates that were reported by Su et al. (2007) for both breeds. This may be due to more deaths after $\mathrm{d} 5$ in the current dataset than reported in the Danish herds. Differences in mortality could be caused by management practices and the fact that the Danish herds (Su et al., 2007; Nielsen et al., 2013) had a higher TNB (greater than 13.5), which may have caused an increase in early deaths proportional to the total number of deaths, increasing the correlation between LS5 and LSW.

With the relatively low genetic correlation between TNB and the 3 weaning traits (LS30, LSW, and NW), there would be a considerable amount of reranking expected between litter size at birth and weaning. Selecting for a trait with more favorable genetic correlations like LS5, LS10, or LSW would be beneficial to increase NW per sow. Since a genetic correlation of 0.95 was reached within the first $8 \mathrm{~d}$ in both breeds, it's expected that there would be only slight reranking of animals after the first week in genetic evaluations. Moreover, later litter size traits had more favorable genetic correlations with BirthWt, a main concern of many swine breeding programs, as low BirthWt piglets lack vitality (Lay et al., 2002).

Correlations between MortD30 and litter size traits started as unfavorable (positive) and became moderately negative by LS5 before stabilizing after LS10. This correlation is one of the reasons it may be more beneficial to use d 10 instead of using an earlier litter size trait. More progress in reducing preweaning mortality would be expected. A practical consideration for which day may be best would be the current litter size means. Given a very high TNB or NBA with a high mortality rate, it may be better to use a day after d 2 or 5 . If the population has a relatively low initial litter size along with a relatively low mortality rate, an earlier day like LS2 may be better for this population.

The genetic correlations between LS5 and NW were exceptionally high in the LW breed (0.96) and in the LR breed (0.85). This difference was likely due to the higher amount of cross-fostering ( 4.9 vs. $8.3 \%$ ) and more deaths later in lactation for the LR breed. This would suggest that it might not be worth it to back calculate litter size traits from piglet data. Instead, simply use the NW value given in existing databases as long as cross-fostering is 
low or eliminated. The answer may come down to initial litter size and cross-fostering. It is expected that a larger initial litter size would result in more cross-fostering. An increase in cross-fostering may result in a lower correlation between LS10 and NW. Breeding programs with lots of cross-fostering or worried about not accounting for this effect may choose a litter size trait such as LS2, which is unaffected by cross-fostering if piglets are moved on d 2. Selection for LS5 has been published; thus, some may choose $\mathrm{d} 5$ because it has been documented to be effective (Nielsen et al., 2013).

\section{Inclusion of Birth Weight in Breeding Programs}

Inclusion of litter BirthWt in breeding programs to improve survival in pigs has previously been suggested (Johnson et al., 1999; Roehe, 1999). However, its effectiveness in terms of reducing preweaning mortalities has been questioned (Knol et al., 2002b; Bidanel 2011). Genetically reducing variation in BirthWt has been thought to have a larger effect than average BirthWt (English and Morrison 1984; Damgaard et al., 2003; Wolf et al., 2008). Results from the present study indicate that increasing the average BirthWt may improve survivability slightly, as the genetic relationship was weak, -0.14 and -0.13 for LW and LR, respectively. Knol et al. (2002b) indicates that it could be a problem with authors interpreting the phenotypic relationship between BirthWt and survival as a genetic correlation. While the phenotypic relationship between BirthWt and survival is well established (Milligan et al., 2002; Fix et al., 2010), the genetic relationship remains weak to moderate $(\mathrm{Su}$ et al., 2008). Damgaard et al. (2003) reported a -0.26 genetic correlation between average BirthWt and proportion of deaths during suckling. Arango et al. (2006) reported genetic correlations of BirthWt with stillbirths, total mortality, and early mortality (before $\mathrm{d} 5$ ) between -0.34 and -0.43 at the direct piglet level and between 0.13 to -0.31 at the maternal level. Genetic correlations seem low to moderate at best. Some of the problem may be because low is a relative term used to describe where a piglet falls in a distribution. Many times, authors decide to describe low in terms of an arbitrary value (e.g., $1 \mathrm{~kg}$ ) instead of using a better measure such as SD from the mean. Increasing the mean does not remove low BirthWt piglets because it does not change the fact that lower BirthWt piglets will have to compete with heavier litter mates (English and Morrison, 1984). Selection for within-litter variation should change the within-litter distribution of BirthWt to increase survivability and give piglets a better chance to compete among themselves. After 4 generations of canalizing selection for BirthWt in rabbits, it was concluded that young rabbit survival was increased without reducing the mean BirthWt (Garreau et al., 2008). When both mean BirthWt and traits related to variability (variance, $\mathrm{SD}$, and $\mathrm{CV}$ ) were analyzed, both resulted in favorable relationships with piglet mortality; however, traits related to variation were more correlated to losses from birth to weaning (Wolf et al., 2008). In the same study, it was also discovered that mean BirthWt was over 3 times more heritable than variability traits (Wolf et al., 2008). A selection index approach would be needed to calculate which trait would result in a higher correlated response or add both into the aggregate genotype if further piglet vitality is desired.

\section{Potential Challenges}

One foreseeable challenge in the future may be the deterioration of the genetic correlation between LS5 and LSW. Estimates thus far have been very high (present study; Su et al., 2007). As selection pressure is applied on LS5, more preweaning mortality deaths might occur after $\mathrm{d} 5$ in response, eroding the high correlation currently observed. Little direct evidence can be provided, as the genetic correlation has not been reported since 2007 in Danish herds. Haley et al. (1988) reported that the genetic correlation between litter size at birth and litter size at weaning was close to unity. Contrast that with the current estimates in this study of 0.55 and the observed association with mortality in breeding programs. When sows were less prolific, before heavy selection pressure on reproductive traits, this correlation would have been substantially higher. Current estimates of prolificacy in Danish herds are over 15 total pigs born (Guo et al., 2015). If the genetic correlation was still 1 as stated by Haley et al. (1988), the trend in TNB and NW should be roughly 1 . Current industry (i.e., commercial) trends show TNB increasing at 0.22 piglets per year and NW at 0.11 piglets per year (Stalder, 2014). Selection for a litter size trait should help parallel these trends by decreasing preweaning mortality.

It is expected that more piglets will be weaned given the results from Nielsen et al. (2013). This means that sows, especially parity 1 sows, will have an increased demand to produce milk, and mothering ability will become even more important. Extrapolating from the dairy industry, genetic correlations between milk yield and fertility traits are unfavorable (Veerkamp et al., 2001); this is most likely due to the negative energy balance from the productivity demands. Wean-to-estrus interval is important economically to producers because it is a component of litters per sow per year, and nonproductive days are costly. Lundgren et al. (2010) investigated the subsequent wean-to-service interval and showed that raising fast-growing piglets may have an effect on subsequent TNB, but no relation to weanto-service interval was found in that study. Lundgren et 
al. (2014) showed that selection for the heaviest litters may lead to lower BCS at weaning and suggested that selection for higher sow feed intake may reduce problems. Although piglet growth and litter size at weaning are not the same trait, both would increase sow productivity. Further investigation into this topic is warranted. Bergsma et al. (2008) suggested including lactation efficiency in the breeding objective as an alternative. Some of these adverse effects may need to be accounted for by adjusting management practices such as increasing lactation feed intake as much as possible and possibly split weaning as litters become larger later in lactation.

\section{Implications}

Since selection for initial litter size has been associated with increased mortality, shifting the breeding objective trait from TNB or NBA to a day early in lactation would be beneficial to reduce mortality while still increasing initial litter size. This simplified trait/model can be used as an alternative to more sophisticated generalized linear mixed-effects models, such as thresholdlinear models, to make an easier transition from selection for initial litter size to a litter size trait later in lactation. No maxima were observed before $\mathrm{d} 30$ in this study; therefore, selection for LSW or LS30 would be optimal, although d 30 was chosen arbitrarily. Selection for LS10 may be a middle ground between progress in litter size at weaning and associated problems with increased nurse sow effects because of cross-fostering and increased additive piglet genetic effects later in lactation. More research needs to be completed on the effect they would have if selection for LSW were practiced. Those programs still concerned with nurse dam effects may choose LS2, assuming they were cross-fostered on d 2, negating its effect. Choosing exactly which day will be left up to individual selection programs and research on a per breeding program basis is needed.

\section{LITERATURE CITED}

Arango, J., I. Misztal, S. Tsuruta, M. Culbertson, J. W. Holl, and W. Herring. 2006. Genetic study of individual mortality and birth weight in Large White piglets using threshold-linear models. Livest. Sci. 101:208-218.

Bidanel, J. P. 2011. Biology and genetics of reproduction. In: M. F. Rothschild and A. Ruvinsky, editors, The genetics of the pig. 2nd ed. C.A.B. International, Oxfordshire, UK. p. 218-241.

Bergsma, R., E. Kanis, M. W. A. Verstegen, and E. F. Knol. 2008. Genetic parameters and predicted selection results for maternal traits related to lactation efficiency in sows. J. Anim. Sci. 86:1067-1080.

Damgaard, L. H., L. Rydhmer, P. Lovendahl, and K. Grandinson. 2003. Genetic parameters for within-litter variation in piglet birth weight and change in within-litter variation during suckling. J. Anim. Sci. 81:604-610.
English, P. R., and V. Morrison. 1984. Causes and prevention of piglet mortality. Pig News Info 5:369-376.

Fix, J. S., J. P. Cassady, J. W. Holl, W. O. Herring, M. S. Culbertson, and M. T. See. 2010. Effect of piglet birth weight on survival and quality of commercial market swine. Livest. Sci. 132:98-106.

Garreau, H., G. Bolet, C. Larzul, C. Robert-Granie, G. Saleil, M. SanCristobal, and L. Bodin. 2008. Results of four generations of a canalizing selection for rabbit birth weight. Livest. Sci. 119:55-62.

Grandinson, K., M. S. Lund, L. Rydhmer, and E. Strandberg. 2002. Genetic parameters for the piglet mortality traits crushing, stillbirth, and total mortality, and their relationship to birth weight. Acta Agriculturae Scandinavica Section A 52:167173.

Guo, X., O. F. Christensen, T. Ostersen, Y. Wang, M. S. Lund, and G. Su. 2015. Improving genetic evaluation of litter size and piglet mortality for both genotyped and nongenotyped individuals using a single-step method. J. Anim. Sci. 93:503-512.

Haley, C. S., E. Avalos, and C. Smith. 1988. Selection for litter size in the pig. Anim. Breed. Abstr. 56:317-332.

Johnson, R. K., M. K. Nielsen, and D. S. Casey. 1999. Responses in ovulation rate, embryonal survival, and litter traits in swine to 14 generations of selection to increase litter size. J. Anim. Sci. 77:541-557.

Knol, E. F., B. J. Ducro, J. A. M. van Arendonk, and T. van der Lende. 2002a. Direct, maternal and nurse sow genetic effects on farrowing-, pre-weaning- and total piglet survival. Livest. Prod. Sci. 73:153-164.

Knol, E. F., J. I. Leenhouwers, and T. van der Lende. 2002 b. Genetic aspects of piglet survival. Livest. Prod. Sci. 78:4755.

Lay, D. C. Jr., R. L. Matteri, J. A. Carroll, T. J. Fangman, and T. J. Safranski. 2002. Preweaning survival in swine. J. Anim. Sci. 80:E74-E86.

Lund, M. S., M. Puonti, L. Rydhmer, and J. Jensen. 2002. Relationship between litter size and perinatal and pre-weaning survival in pigs. Anim. Sci. 74:217-222.

Lundgren, H., L. Canario, K. Grandinson, N. Lundeheim, B. Zumbach, O. Vangen, and L. Rydhmer. 2010. Genetic analysis of reproductive performance in Landrace sows and its correlation to piglet growth. Livest. Sci. 128:173-178.

Lundgren, H., W. F. Fikse, K. Grandinson, N. Lundeheim, L. Canario, O. Vangen, D. Olsen, and L. Rydhmer. 2014. Genetic parameters for feed intake, litter weight, body condition and rebreeding success in primiparous Norwegian Landrace sows. Animal 8:175-183.

Merks, J. W. M., P. K. Mathur, and E. F. Knol. 2012. New phenotypes for new breeding goals in pigs. Animal 6:535-543.

Milligan, B. N., D. Fraser, and D. L. Kramer. 2002. Within-litter birth weight variation in the domestic pig and its relation to pre-weaning survival, weight gain, and variation in weaning weights. Livest. Prod. Sci. 76:181-191.

Misztal, I., S. Tsuruta, T. Strabel, B. Auvray, T. Druet, and D. H. Lee. 2002. BLUPF90 and related programs (BGF90). Proc. 7th World Congr. Genet. Appl. Livest. Prod., Montpellier, France.

National Pork Board. 2003. Swine care handbook. National Pork Board, Des Moines, IA. http://porkcdn.s3.amazonaws.com/ sites/all/files/documents/AnimalWell-Being/swine \%20 care\%20handbook\%202003.pdf (Accessed 24 August 2015.) 
Nielsen, B., G. Su, M. S. Lund, and P. Madsen. 2013. Selection for increased number of piglets at d 5 after farrowing has increased litter size and reduced piglet mortality. J. Anim. Sci. 91:2575-2582.

Roehe, R. 1999. Genetic determination of individual birth weight and its association with sow productivity traits using Bayesian analyses. J. Anim. Sci. 77:330-343.

Stalder, K. J. 2014. 2014 U.S. pork industry productivity analysis. National Pork Board. Des Moines, IA. http://old.pork.org/ filelibrary/ipafull14.pdf (Accessed February 15, 2015.)

$\mathrm{Su}$, G., M. S. Lund, and D. Sorensen. 2007. Selection for litter size at day five to improve litter size at weaning and piglet survival rate. J. Anim. Sci. 85:1385-1392.
Su, G., D. Sorensen, and M. S. Lund. 2008. Variance and covariance components for liability of piglet survival during different periods. Animal 2:184-189.

Tsuruta, S. 2015. Approximate variance for heritability estimates. http://nce.ads.uga.edu/html/projects/AI_SE_revised.pdf. (Accessed 30 April 2015.)

Veerkamp, R. F., E. P. C. Loenen, and G. De Jong. 2001. Genetic correlations among body condition score, yield, and fertility in first-parity cows estimated by random regression models. J. Dairy Sci. 84:2327-2335.

Wolf, J., E. Zakova, and E. Groeneveld. 2008. Within-litter variation of birth weight in hyperprolific Czech Large White sows and its relation to litter size traits, stillborn piglets and losses until weaning. Livest. Sci. 115:195-205. 